\title{
Review of the performance of residential PV systems in France
}

\author{
Jonathan Leloux ${ }^{\mathrm{a}, *}$, Luis Narvarte ${ }^{\mathrm{a}}$, David Trebosc ${ }^{\mathrm{b}}$ \\ a Instituto de Energía Solar, ETSI Telecomunicación, Ciudad Universitaria, s/n, 28040 Madrid, Spain \\ ${ }^{\mathrm{b}}$ BDPV, Rue du Capitaine Fracasse, 1, 31320 Castanet Tolosan, France
}

\section{A R T I C L E I N F O}

\section{Keywords:}

Residential PV system

Energy production

Performance Ratio

Performance Index

CIS

HIT

PI

France

\begin{abstract}
A B S T R A C T
The main objective of this paper is to review the state of the art of residential PV systems in France. This is done analyzing the operational data of 6868 installations. Three main questions are posed. How much energy do they produce? What level of performance is associated to their production? Which are the key parameters that most influence their quality? During the year 2010, the PV systems in France have produced a mean annual energy of $1163 \mathrm{kWh} / \mathrm{kW}_{\mathrm{p}}$. As a whole, the orientation of PV generators causes energy productions to be some $7 \%$ inferior to optimally oriented PV systems. The mean Performance Ratio is $76 \%$ and the mean Performance Index is $85 \%$. That is to say, the energy produced by a typical PV system in France is $15 \%$ inferior to the energy produced by a very high quality PV system. On average, the real power of the PV modules falls $4.9 \%$ below its corresponding nominal power announced on the manufacturer's datasheet. A brief analysis by PV modules technology has led to relevant observations about two technologies in particular. On the one hand, the PV systems equipped with heterojunction with intrinsic thin layer (HIT) modules show performances higher than average. On the other hand, the systems equipped with the copper indium (di)selenide (CIS) modules show a real power that is $16 \%$ lower than their nominal value.
\end{abstract}

\section{Contents}

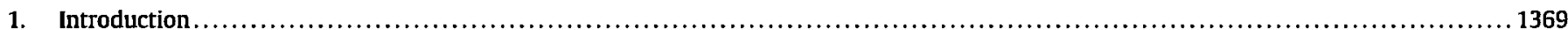

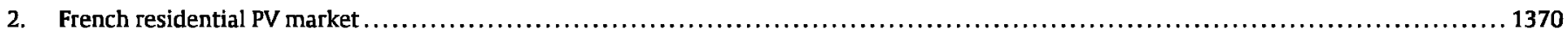

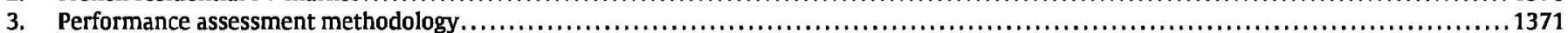

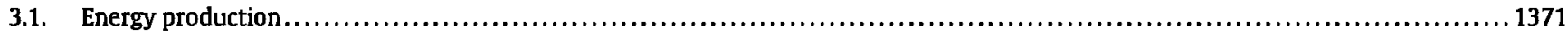

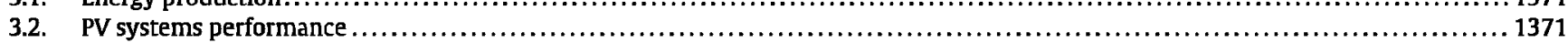

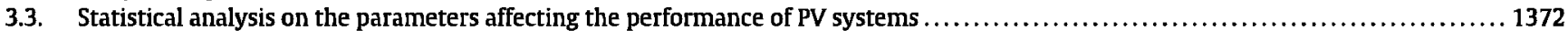

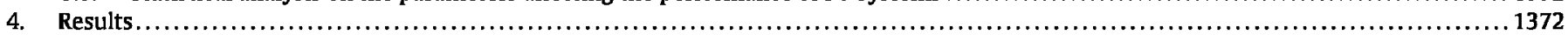

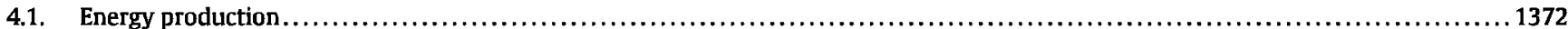

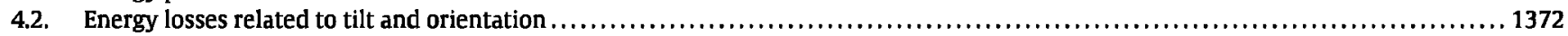

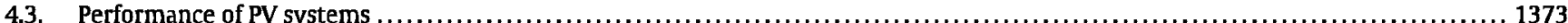

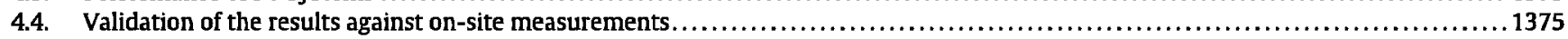

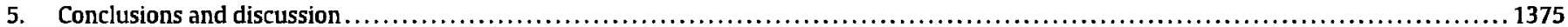

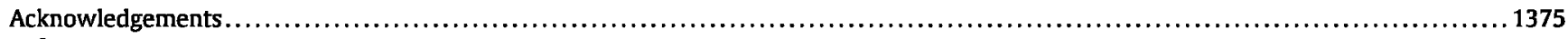

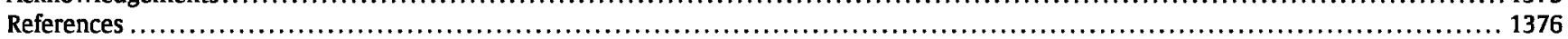

\section{Introduction}

The main objective of this paper is to review the state of the art of residential PV systems in France. This is done analyzing the

\footnotetext{
* Corresponding author. Tel.: +3491453 35 58; fax: +349145335 58 E-mail addresses: jonathan.leloux@ies-def.upm.es, jonathan.leloux@yahoo.es
} (J. Leloux). operational data of a representative sample of 6868 installations, totalizing a peak power of approximately $20.5 \mathrm{MW}$, and installed between 2007 and 2010. At the end of March 2011, 1146 MW were installed in Metropolitan France [1]. About half of the total power is installed in residential PV systems of less than $10 \mathrm{~kW}_{\mathrm{p}}$. The database here considered represents approximately $3.5 \%$ of the residential PV in Metropolitan France at the end of March 2011.

The study articulates the analysis around three questions: 
(1) How much electricity do PV systems produce in terms of kWh per kWp?

(2) What is their performance for producing electricity? The PV systems quality is analyzed using different performance indicators such as the Performance Ratio (PR), the performance ratio at standard test conditions (STC), condensed as PR STC $_{\text {and }}$ the Performance Index (PI).

(3) Which are the key aspects that influence the quality of PV systems? Statistical tools are applied to find them out.

For the first question, related to energy production, a survey is realized over the monthly energy production data supplied by the PV systems' owners through a Website [2].

For the second question, related to the performance of PV installations, the assessment is based on the aforementioned performance indicators, all of them consisting on comparing the real energy production of each of the systems with the production simulated for a corresponding hypothetical system used as a reference.

For the third question, an analysis-of-variance (ANOVA) applied on the PI uncovers the key aspects that influence the quality of PV systems. A general multidimensional ANOVA is realized by grouping the PV systems according to four characteristics: PV modules manufacturer, inverters manufacturer, installer, and PV generator power. The goal is to isolate the causes explaining the $P I$ differences.

The results presented in this work allow extracting conclusions about the expected energy production of PV residential systems representative of the state of the art. They quantify the energy production losses due to the orientation of the PV generators. The important quantity of PV systems analyzed makes it possible to extend the results not only to the French market, but also to the European one and, hence, they are of general interest. In fact, the conclusions are congruent with previous analyses of the operational performance of residential PV systems installed during the last two decades in Germany, Switzerland, Italy, Spain, Netherlands, Japan, Taiwan, Brazil and USA [3-8], and can be useful to important works that are presently ongoing [9] and whose main purpose is the assessment of the performance and reliability of PV systems.

\section{French residential PV market}

The data analyzed in the present study concerns Metropolitan France (i.e. excluding Overseas France). PV experienced there an important growth since the year 2004, with the establishment of a tax credit of $40 \%$ of the PV system cost. The growth was accelerated in 2005 with the rise of that tax credit up to $50 \%$. But the decisive moment was the vote in $\mathbf{2 0 0 6}$ of a new feed-in tariff specific to PV of at least $0.30 \Theta / \mathrm{kWh}$, and up to $0.46 \Theta / \mathrm{kWh}$ for building integrated photovoltaics (BIPV). As a direct consequence, from the year 2007, the number of residential PV systems started to take off, reaching $20 \mathrm{MW}$ at the end of that year. At the end of March 2011, residential PV systems represented more than $550 \mathrm{MW}$. That power was distributed over more than 160,000 installations.

Fig. 1 shows that $98 \%$ of the residential PV systems installed in France have a peak power of $3 \mathrm{~kW}_{\mathrm{p}}$ or less, and more than half of the installations have a peak power very close to $3 \mathrm{~kW}$. This situation arose as a direct consequence of a legal frame that strongly discourages installations of more than $3 \mathrm{~kW}$, mainly for two reasons. First, the tax credits are denied for the PV systems of more than $3 \mathrm{~kW}_{\mathrm{p}}$. Second, a VAT of $5.5 \%$ is applied to systems of less than $3 \mathrm{~kW}_{\mathrm{p}}$, while it jumps to $19.6 \%$ for systems of more than $3 \mathrm{~kW}$. The power distribution among residential PV systems in France is thus mainly explained by legal considerations, rather that technical ones.

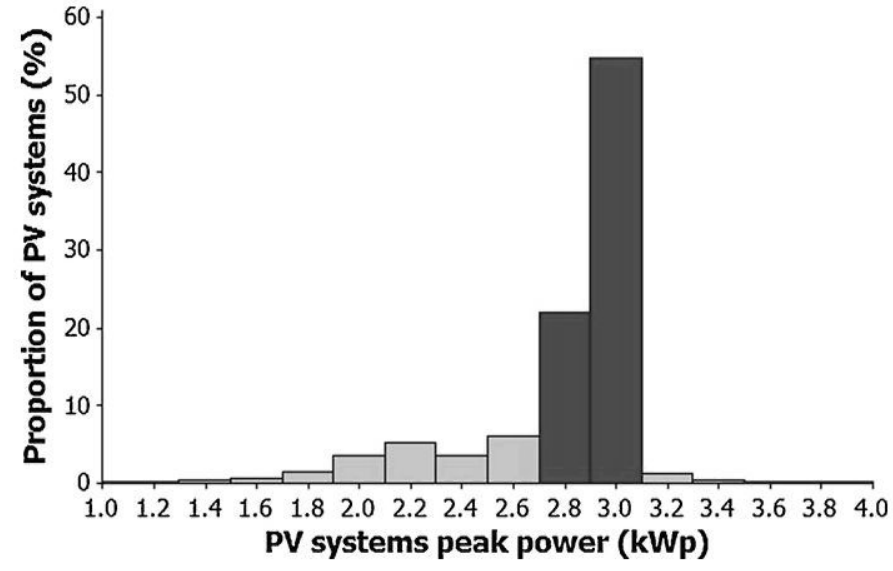

Fig. 1. Histogram of the peak power of PV systems. Nearly $98 \%$ of the residential PV systems installed in France have a peak power of $3 \mathrm{~kW}_{\mathrm{p}}$ or less, and more than half of the installations have a peak power very close to $3 \mathrm{~kW}$.

In our database, PV modules based on classical crystalline sili$\operatorname{con}(\mathrm{xSi})$ technology represent about $78 \%$ of the total market shares. The rest of the market is distributed, by order of importance, among heterojunction with intrinsic thin layer (HIT) (17\%), amorphous silicon (aSi) (2\%), copper indium (di)selenide (CIS) (2\%), and cadmium telluride (CdTe) (1\%).

The database contains $106 \mathrm{PV}$ modules manufacturers, 21 inverters manufacturers and 423 PV systems installers. Fig. 2 shows that the relative market penetration within PV modules and inverters manufacturers is satisfactorily modeled by a power-law, indicating that the market is dominated by a reduced number of actors. The most extreme case of market domination is the control of more than $50 \%$ of the market by one single inverter manufacturer (the point corresponding to that inverter manufacturer is not represented in Fig. 2 because it is out of scale, but is taken into account in the power-law equation). The leading PV modules manufacturer distributes a HIT technology and has a market share of 17\%. The installers market does not follow a power-law mainly because many installers are small familiar enterprises that only work at local scales, much smaller than the country.

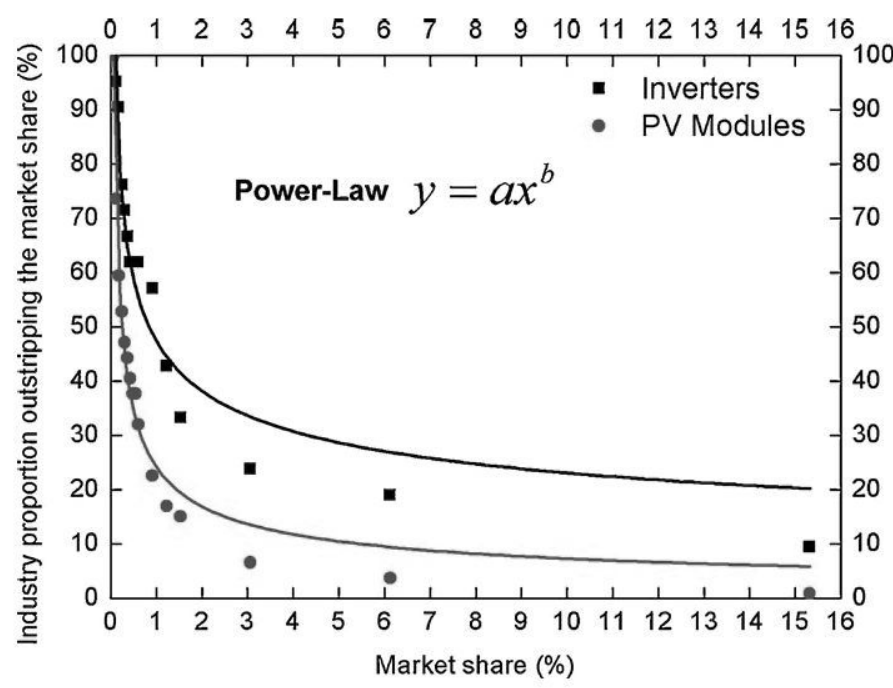

Fig. 2. Relative portion of the PV industry outstripping a given market share. The relative market penetration for PV modules and inverters manufacturers is satisfactorily modeled by a power-law. The R-squares of the fits yield 97.5\% for the PV modules, and $91.9 \%$ for the inverters. 


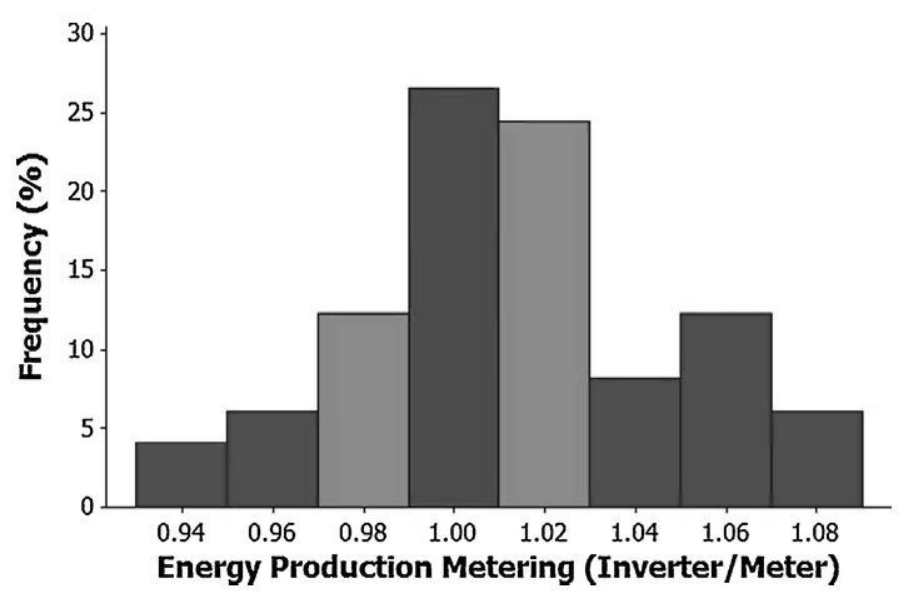

Fig- 3. Histogram of the relation between the energy metering by inverter and meter.

\section{Performance assessment methodology}

\subsection{Energy production}

As mentioned earlier in the text, the data concerning the PV systems were supplied by their owners. Each PV system is localized by its latitude and longitude, completed with the corresponding altitude. The PV generator is characterized by its orientation and tilt angles, its total surface, and its total peak power. The data also provides information about the manufacturers of the PV modules and inverters that equip the system, and the installer. The net energy production is reported on a monthly basis, and is read at the inverter (95\% of the database), or at the meter (20\%), or at both sources (15\%). The PV owners also communicated the annual energy that they expected to produce, and that was generally estimated by the installer before the commissioning of the installation. Not all the PV owners reported the energy production corresponding to each month, and only $25 \%$ of them reported it systematically and correctly.

Thanks to the PV owners that simultaneously provided the energy production data coming from both the inverter and the meter, it was possible to compare both sources of information. Fig. 3 shows the results of these comparisons. The ratio $E_{\text {inverter }} / E_{\text {meter }}$ shows values ranging from 0.93 to 1.09 . A ratio superior/inferior to 1 indicates that the inverter systematically overestimates/underestimates the energy produced. When the inverters are grouped by manufacturer and model, these ratios show a much lower dispersion, which shows that some inverters systematically overestimate/underestimate the energy that is really produced. Therefore, in the present study, the data provided by the inverters are adjusted by comparison with the data provided by the energy meters.

\subsection{PV systems performance}

The performance of PV systems is realized by comparison with a corresponding reference system. The simulations require the input of the horizontal solar radiation and the ambient temperature data, both on a monthly basis, which have been obtained from SoDa [10] and PVGIS [11], respectively. The solar radiation received on the surface of each of the PV generators is estimated using widely accepted solar radiation models [12-14]. The estimation of the energy production of the reference system is simulated with a tool developed at IES-UPM and based on widely accepted models, whose details have been described elsewhere [15-22].
Table 1

The quality of a PV system for producing energy can be described through three different performance indicators: $P R, P R S T C$ or $P I$.

\begin{tabular}{|c|c|c|}
\hline Indicator & Definition & Reference system \\
\hline $\begin{array}{l}\text { Performance } \\
\text { Ratio }\end{array}$ & $\begin{array}{l}\text { PR }=E_{\text {produced }} / \frac{p^{S T C}}{G T C} \int G d t \text {, } \\
\text { where } E_{\text {produced }} \text { is the net } \\
\text { electrical energy produced } \\
\text { by the PV system during a } \\
\text { given period of time, PrTC is } \\
\text { the rated power of the PV } \\
\text { generator under STC, } G^{\text {STC }} \\
\text { is the global solar } \\
\text { irradiance under STC (i,e. } \\
1000 W / m^{2} \text { ), and } G \text { is the } \\
\text { global solar irradiance } \\
\text { received by the PV } \\
\text { generator. }\end{array}$ & $\begin{array}{l}\text { Free of any kind of system } \\
\text { losses. Jts solar cells are } \\
\text { always kept at } 25^{\circ} \mathrm{C} \text {. }\end{array}$ \\
\hline $\begin{array}{l}\text { Performance } \\
\text { Ratio at STC }\end{array}$ & $\begin{array}{l}\mathrm{PR}_{\text {STC }}= \\
E_{\text {produced }} / \frac{\text { PSTC }}{\mathrm{C}^{\text {STC }}} \int \mathrm{G}(1- \\
\left.\Delta P_{\text {STC }}\right) d t \text {, where } \Delta P_{\text {STC }} \\
\text { represents the thermal } \\
\text { power losses in the PV cells } \\
\text { due to their operational } \\
\text { temperature which is } \\
\text { different than STC. }\end{array}$ & $\begin{array}{l}\text { Free of any kind of system } \\
\text { losses. Its solar cells } \\
\text { operate at the same } \\
\text { temperature that the ones } \\
\text { of the system to be } \\
\text { compared with. }\end{array}$ \\
\hline $\begin{array}{l}\text { Performance } \\
\text { Index }\end{array}$ & $\begin{array}{l}\mathrm{Pl}=E_{\text {produced }} / \frac{\mathrm{P}_{\mathrm{STC}}}{G \mathrm{STC}} \int G(1- \\
\left.\Delta P_{\mathrm{STC}}\right)\left(1-\Delta \mathrm{P}_{\mathrm{DC} / \mathrm{AC}}\right) d t \text {, } \\
\text { where } \Delta P_{\mathrm{DC} / \mathrm{AC}} \text { represents } \\
\text { the conversion losses due } \\
\text { to the inverter that equips } \\
\text { the reference system. }\end{array}$ & $\begin{array}{l}\text { High quality PV system. } \\
\text { Almost free of system } \\
\text { losses, except mainly the } \\
\text { cell's temperature losses } \\
\text { and the DC/AC losses } \\
\text { corresponding to a very } \\
\text { good inverter and } \\
\text { considered somewhat } \\
\text { unavoidable. }\end{array}$ \\
\hline
\end{tabular}

The energy performance indicators that are used to assess the technical quality of a particular PV system are obtained by comparing its actual production along a certain period of time with the production of a hypothetical reference system (of the same nominal power, installed at the same location, and oriented the same way) somewhat free of certain kinds of losses. Table 1 presents three different performance indicators that are used to assess the quality of a PV system. All three compare the real energy production of the PV system during a certain period of time to the corresponding reference system. The variation between them comes from the different reference system that is chosen in each case.

The $P R$ is, by far, the most widely used performance indicator today, because the unitary energy production, which is of paramount importance for economic analyses, is simply given by the product of the irradiance (or the number of "sun-hours"), by the $P R$. The difference between 1 and $P R$ lumps together all imaginable energy losses (real power of the PV modules power below nominal rating, mismatch, wiring, shades, dust, thermal, DC/AC, failures, etc.). Because thermal losses are site-dependent (they depend on climate), the $P R$ of a given, unchanged PV system fluctuates from one place to another, and along the course of a year or a day, which represents an obvious inconvenient for strictly qualifying its technical quality. The $P R$ of a given PV system located in the North of France is higher than the $P R$ of the same system installed in the South of the country. The $P R_{S T C}$ takes away such thermal losses, which requires to consider (measure or estimate) the temperature of operation of the solar cells. Because of that, it is of more complex calculation than the PR, but it becomes practically independent from time and site, thus being more appropriate for strictly qualifying technical quality on a comparative basis. However, the $P R_{\text {STC }}$ value corresponding to an excellent quality and properly maintained PV system is lower than 1, mainly because real inverters always associate some energy losses to the DC/AC conversion. Hence, one further step can still be taken subtracting the DC/AC conversion losses corresponding to a top class inverter, let us say, 


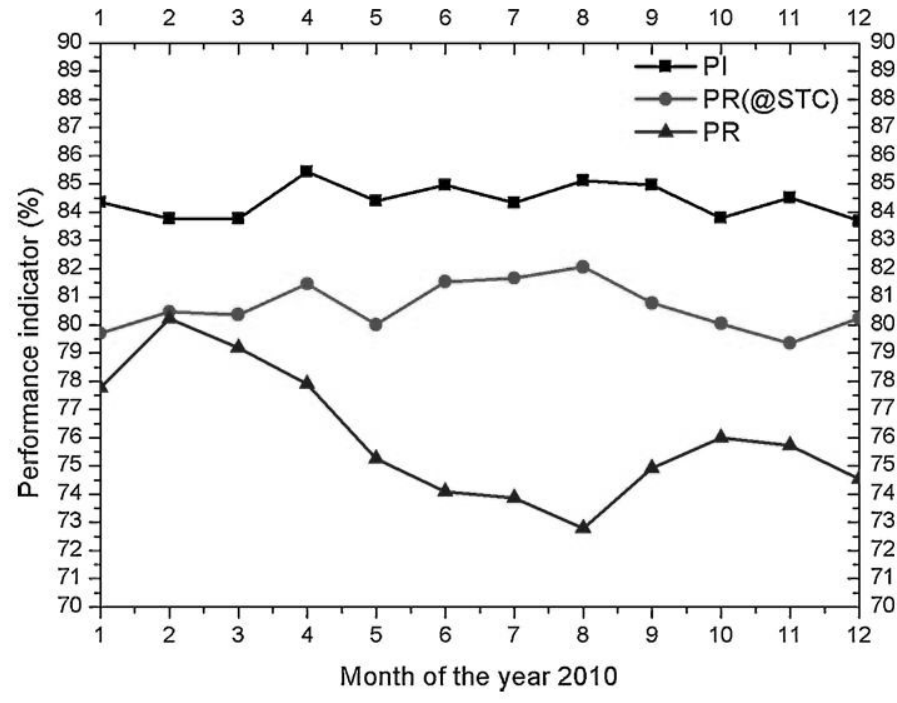

Fig. 4. Evolution of $\mathrm{Pl}, \mathrm{PR}_{\mathrm{TTC}}$ and $\mathrm{PR}$ for a PV system during the year 2010.

\section{Table 2}

General methodology used for the assessment of the performance of residential PV systems.

1. Data collection at each location

PV systems monthly real energy production [2]

PV systems main characteristics: PV generator peak power, surface, tilt and

orientation, PV modules and inverters models, installers, general comments about the system [2]

Monthly global horizontal radiation [10]

Monthly $T_{\max }$ and $T_{\min }[11]$

II. Solar radiation on PV generators

Clearness indexes for global and diffuse radiation [12]

Daily global, direct and diffuse radiation [13]

Global radiation on PV generator surface [14]

III. Calculation of Performance Ratio (PR)

Rated power under STC [2]

IV curve under outdoor conditions [16]

$\mathrm{PR}=$ ratio (real energy production/energy production without system losses)

IV. Calculation of Performance Index (PI)

Losses due to cell temperature [17]

Spectral losses [18,19]

Inverter electrical model [20]

P]-ratio (real energy production/energy production for reference system)

one whose European efficiency is $96 \%$. That leads to the so called $P I$ [23]. It should be noted that a $P I=1$ corresponds to a PV system composed by an inverter and a PV generator whose real power and characteristics coincide with their rated nominal value, free of shading, dust and wiring losses and also free of failures. Consequently, the difference between 1 and PI can be understood as a measure of the somewhat avoidable energy losses. The PI thus allows comparing directly the quality of PV systems under different climatic and installation conditions. Because of that, this paper pays particular attention to the analysis of $P I$ values. Fig. 4 shows the evolution during the year 2010 of both PI and PR for a typical PV system of the sample, free of shading, not experiencing any lack of availability or other second order problems, whose $P I$ is $84 \%$, whose $P R_{\text {STC }}$ is $80.5 \%$ and whose $P R$ is $76.5 \%$ (all in annual values). The $P I$ is relatively constant along the year, while the $P R$ varies of some $10 \%$ between winter and summer, mainly due to the evolution of cell's temperature. This lesser fluctuation of $P I$ respect to $P R$ suggests that $P I$ is a better quality indicator of the quality of PV systems than PR.

Table 2 summarizes step by step the methodology used to calculate the performance indicators.

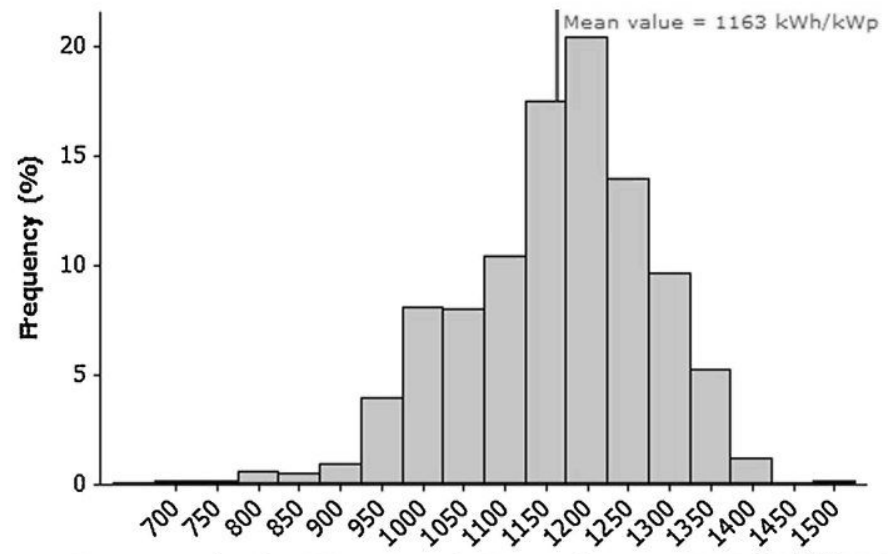

Energy production PV systems in France for year 2010 (kWh/kWp)

Fig. 5. Histogram of the production of the PV systems in 2010.

\subsection{Statistical analysis on the parameters affecting the performance of PV systems}

To investigate furthermore the main causes of the quality differences observed among the PV systems, they have been grouped by common properties. The statistical method analysis-of-variance (ANOVA) has been used to study the causes of the dispersion of PI. ANOVA procedures rely on a distribution called the $F$-distribution. The key statistic is $F=$ MSTR/MSE, where mean square treatment (MSTR) represents the variation among the means of the different groups, and mean square error (MSE) represents the variation within the groups. Large values of $F$ indicate that the variation among the groups is large relative to the variation within the groups, and hence that the groups are significantly different. A general multidimensional ANOVA was realized according to four grouping criteria: PV modules manufacturer, inverters manufacturer, installer, and PV system peak-power.

\section{Results}

\subsection{Energy production}

The energy production analysis is carried out for the year 2010 and for the 1635 PV systems from which the monthly production was correctly reported for the 12 months of the year. Fig. 5 shows a histogram of those energy productions. On average, the PV systems produced in 2010 a net annual energy of $1163 \mathrm{kWh} / \mathrm{kW}$. The dispersion is mainly due to three factors: geography (and therefore solar radiation and temperature), orientation and performance. The solar radiation during the year $\mathbf{2 0 1 0}$ in France was globally comparable to the mean radiation during the last decade. The energy productions reported are thus sufficiently representative to be compared with other previous studies in the literature. As a comparison, annual productions around $800 \mathrm{kWh} / \mathrm{kW}_{\mathrm{p}}$ were reported for PV systems installed 5-10 years ago in the North and East of Germany [3]. Two main causes explain the lower productions reported for the PV systems in Germany respect to France. First, the solar radiation is globally higher in France. Second, the energy productions reported in Germany correspond to PV systems installed about 10 years ago, whose quality was probably lower, and whose power has decreased with time, mainly due to the light soaking.

\subsection{Energy losses related to tilt and orientation}

The vast majority of PV generators have a tilt angle between $20^{\circ}$ and $50^{\circ}$, which generally corresponds to the configuration of the 


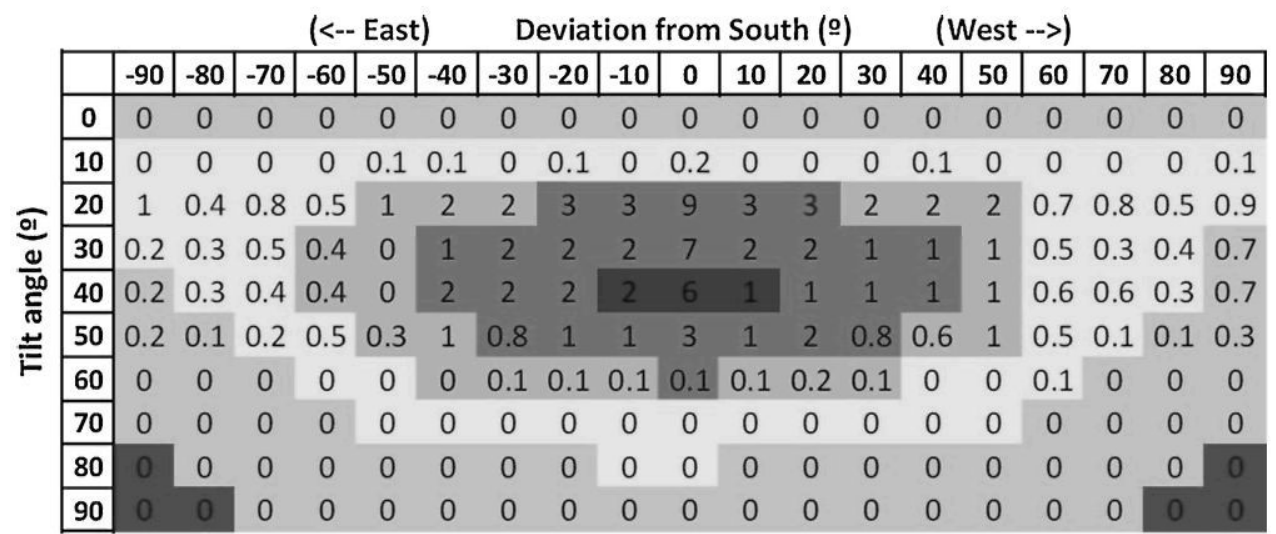

Numbers: Proportion of PV systems installed (\%)

Colors: Annual energy production ( $E$ in \%) relative to $M A X=100 \%$

$95>E \geq 9090>E \geq 80 \quad 80>E \geq 60$

Fig. 6. Distribution of the number of PV systems installed (out of a total number of 6868), in function of the orientation and tilt, together with the corresponding net annual energy produced by a PV system in France respect to the optimal inclination (in $\%$ ).

roofs on which they are mounted. At the latitudes of France, from $43^{\circ}$ to $51^{\circ}$ North, a PV generator maximizes its annual energy produced when it faces South and benefits from a tilt angle around $40^{\circ}$. When the orientation is different, which is usual in residential PV, the energy produced diminishes by an amount that is shown in Fig. 6. That same figure also shows the relative distribution, in percent, of the number of residential PV systems installed, in function of the orientation and tilt. It is worth underlying that low tilt values favor dust accumulation (tilt angles of less than $10^{\circ}$ have been reported to keep hold of important quantities of dust [24]), but Fig. 6 shows that it is not frequent to find those low tilt values.

Fig. 7 shows the relation between the energy losses due to orientation and the proportion of PV systems installed. It is satisfactorily described by a power-law $\left(R^{2}=97.5 \%\right.$ ). Almost $65 \%$ of the PV systems loose less than $5 \%$ of their annual energy due to orientation, and less than $10 \%$ lose more than $15 \%$. As a whole, the orientation of residential PV causes energy productions to be $7 \%$ inferior to optimally oriented PV systems, which can be interpreted as the price to pay, in terms of energy losses, for installing PV systems on roofs instead of installing PV farms.

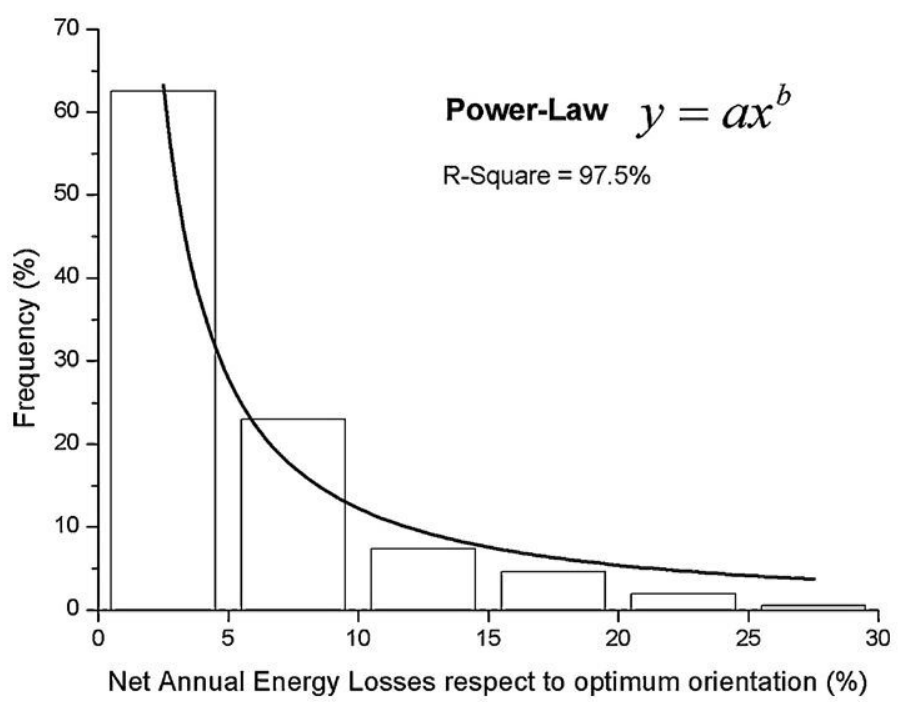

Fig. 7. Proportion of PV systems (in \%) oriented so that they lose less than a given percentage of net annual energy respect to the optimum orientation. Almost $65 \%$ of the PV systems lose less than $5 \%$ of annual energy due to their orientation, and less than $10 \%$ lose more than $15 \%$

\subsection{Performance of PV systems}

Fig. 8 presents the histogram of PR and PI of 1635 PV systems that correctly provided the monthly produced energy for the year 2010. The mean value of $P I$ is very close to $85 \%$, which indicates that, on average, the PV systems are producing an annual energy that is $15 \%$ inferior to the reference system. The $P I$ observed in 2010 tends to be slightly higher for newer installations. The mean PI measured in $\mathbf{2 0 1 0}$ for PV systems installed in 2007, 2008 and 2009 yielded, respectively, $82.9 \%, 83.5 \%$ and $85.5 \%$. Two main causes probably explain that trend. First, the power of PV modules is known to decrease with time due to the light soaking. Second, quality controls have been given a growing importance during these last years. It was not possible to track PI values from previous works to compare them with the ones obtained in the present study. To make possible a direct comparison using the more widely spread concept of $P R$, Fig. 8 shows its corresponding histogram. The mean value of $P R$ is 76\%. As a comparison, values of PR between $48 \%$ and $93 \%$ have been reported in other works $[25,26]$.

The distribution of $P I$ is nearly normal between values from $70 \%$ to $100 \%$. It is left skewed, which physically arises from the existence of PV systems suffering from major issues and thus showing PI values abnormally low, while even a very good PV system can hardly have a PI much higher than 100\%. The skewness can be approximated through a Weibull distribution (at a confidence level of 95\%, Anderson-Darling goodness of fit $=1.452$ ). The distribution of $P R$ is more symmetrical, mainly because the influence of cell's temperature on the $P R$ introduces wider variation among the PV systems installed in different climatic conditions.

In order to look for the causes that explain the PI differences among the different PV residential systems, an ANOVA was applied to the whole database. It did not allow associating significant variations of $P I$ to the nominal power of the installations, the inverter manufacturers or the installers. This failure to identify significant trends does not imply the absence of differences. It simply means that the PI differences cannot be statistically attributed to any of these parameters with a sufficient confidence level.

The ANOVA did however allow to establish strong evidence that the PV modules explain the majority of the dispersion of $P I$ $(F-23.21$ and $P$-value $<0.001)$. The results of this ANOVA for PV modules that are present on at least 25 installations are detailed in Table 3. Manufacturers' names have been hidden under symbols for confidentiality reasons. xSi stands for crystalline silicon; bcSi stands for back-contact silicon; HIT stands for Heterojunction with 

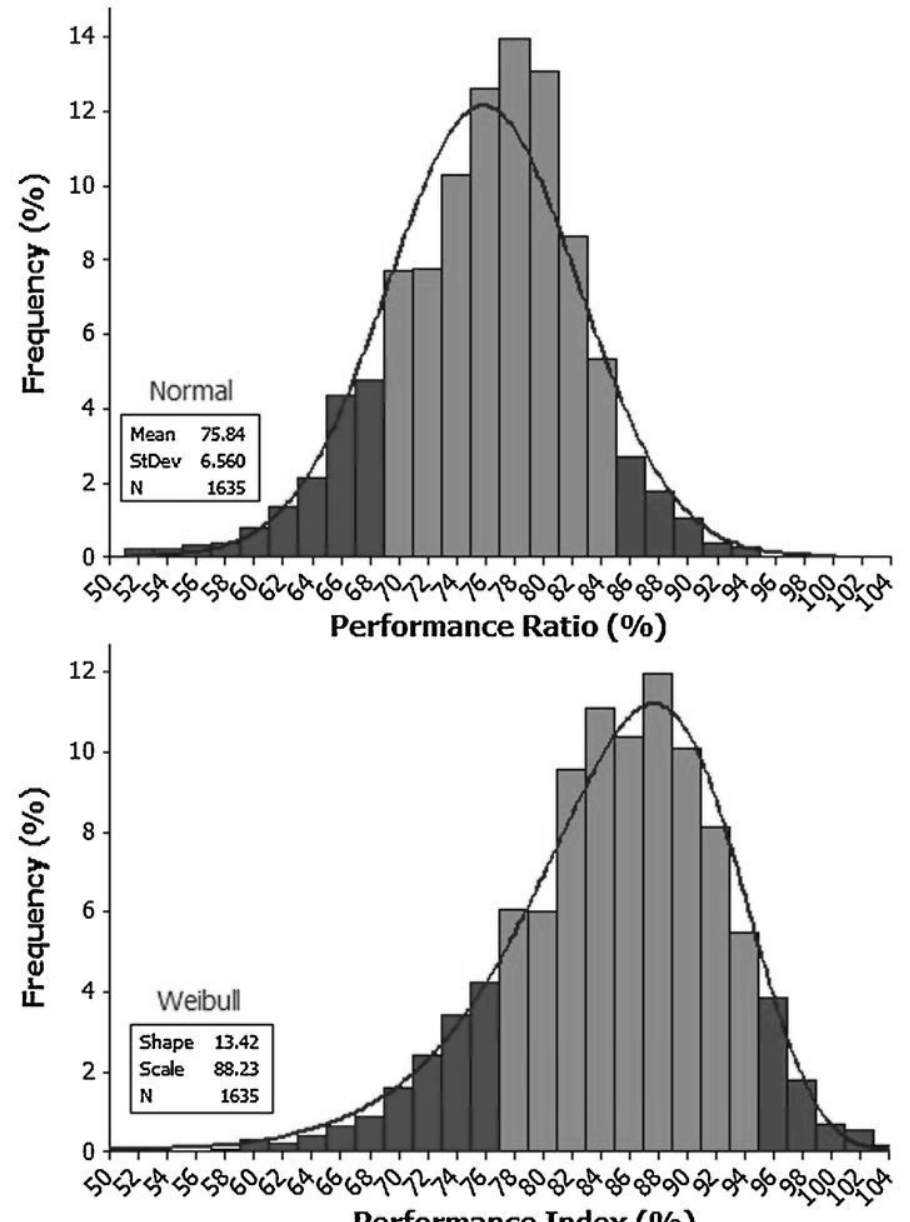

Performance Index (\%)

Fig. 8. Histogram of the Performance Ratio (above) and Performance Index (below) of the PV systems analyzed. The distribution is nearly normal between a PI value of $70 \%$ and 100\%. The distribution is left skewed. The skewness is modeled through a Weibull distribution. The distribution of $P R$ is more symmetrical, mainly because the influence of cell's temperature on the PR introduces wider variation among the PV systems installed in different climatic conditions.

Table 3

ANOVA on PV modules present at least on 25 PVinstallations. Nindicates the number of installations. The ANOVA analysis on PV modules shows significant differences between the mean power of several groups of PV madules.

\begin{tabular}{lrll}
\hline PV Module & $N$ & Mean of PI $(\boldsymbol{x})$ & StDev of PI (\%) \\
\hline bcSi1 & 47 & 83.7 & 6.2 \\
CIS1 & 26 & 72.7 & 6.5 \\
HIT1 & 283 & 88.7 & 6.1 \\
xSi1 & 27 & 86.0 & 4.3 \\
xSi2 & 32 & 83.6 & 8.8 \\
xSi3 & 45 & 85.4 & 7.0 \\
xSi4 & 70 & 79.3 & 8.1 \\
xSi5 & 146 & 83.9 & 7.2 \\
xSi6 & 137 & 87.2 & 6.5 \\
xSi7 & 43 & 87.5 & 5.5 \\
xSi8 & 127 & 87.9 & 6.8 \\
xSi9 & 41 & 85.8 & 6.9 \\
\hline
\end{tabular}

Intrinsic Thin layer; CIS stands for CuInSe2 based solar cell (thin film). Among the results, it is possible to draw important observations about two PV modules technologies. On the one hand, the PV systems equipped with the module tagged as "HIT1" show PI values higher than average. This module is also the most represented on the PV systems of the database. On the other hand, the systems equipped with the PV module tagged as "CIS" clearly show a PI pretty low respect to all the other groups.

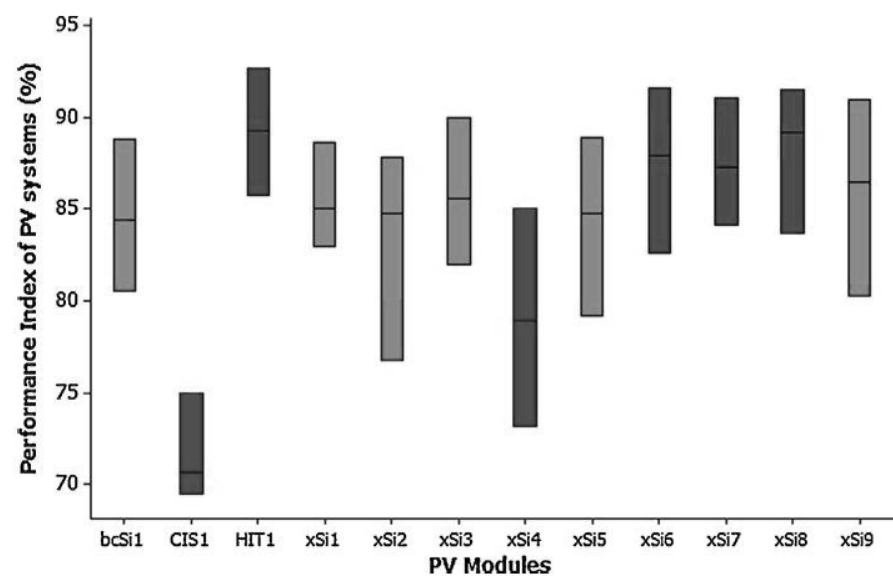

Fig. 9. Boxplot of Performance Index for PV modules present at least on 25 PV installations. The boxes show the first, second and third quartiles, represented respectively by the lower, medium and upper horizontal lines. The second quartile is also the median.

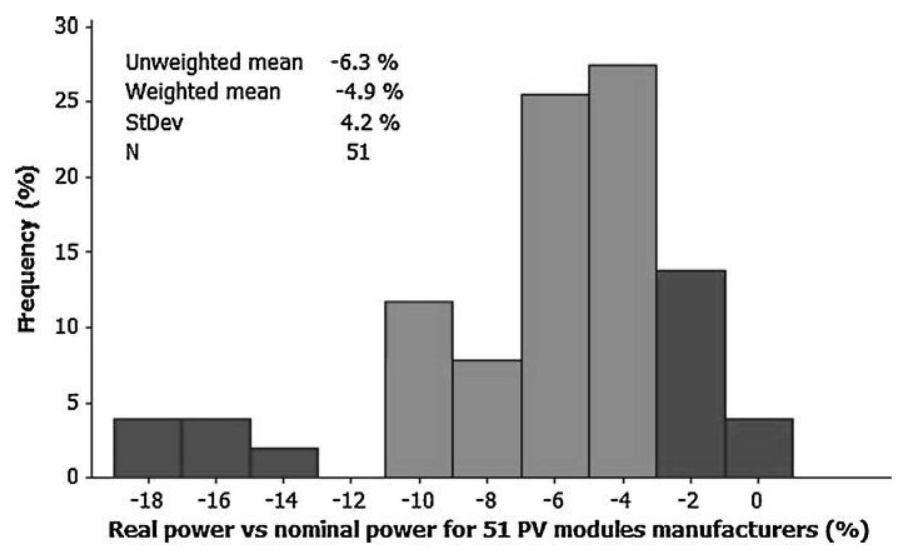

Fig. 10. Histogram of the deviation of the real power of the PV modules respect to their nominal power. On average, the PV modules real power falls $4.9 \%$ below their corresponding nominal power.

Fig. 9 shows a boxplot that allows visualizing the PI variations among and within the groups of PV modules.

In order to estimate the real power of the PV modules, we assume that the losses due to the Balance Of System (BOS) are 10\% higher than in the reference system. This assumption is supported by previous works that describe the losses typically present at a PV system. The soiling losses typically account for $3 \%[21,22]$. The average inverter has a yield $2 \%$ lower than the high quality inverter that equips the reference system [27]. PV generator mismatch and wiring losses can typically be $2 \%$ higher than in the reference system [28]. Shading can lead to important energy losses in some cases. The evaluation of shading losses is particular to each project and often implies complex models. The shading losses were not simulated for each PV system, but were instead estimated to $2 \%$ on average, which seems a reasonable hypothesis for the typical residential PV systems in France [29]. Other losses, such as the ones due to the availability of the system, can account for $1 \%$ [30]. Those losses can thus be estimated conservatively to account for $10 \%$ of annual energy losses. As the mean value of $P I$ is $85 \%$, there is a $5 \%$ left that is probably due to a power default in the PV modules.

Under those assumptions, it is possible to group the PV modules by manufacturer and to estimate the deviation of their real power respect to their corresponding nominal power announced by the manufacturer. Fig. 10 shows the result of this exercise for 51 different manufacturers of PV modules. It is worth mentioning that the PV modules analyzed here have a mean exposure time of 2 years. 
Table 4

Comparisons between real and nominal powers estimated in this work, and measured by IES-UPM on solar plants in Spain, Italy and France.

\begin{tabular}{lcrr}
\hline PV module(Hidden names) & Real vs nominal power (\%)[this work] & \multicolumn{1}{c}{ Real vs nominal power (\%)[on-site measurements] } & Difference (\%) \\
\hline PV1 & -6.4 & -7.1 & -1 \\
PV2 & -4.6 & -3.1 & 0.7 \\
PV3 & -10.7 & -12.3 & -2.1 \\
PV4 & -1.3 & -4.7 & \\
PV5 & -6.1 & -5.2 & -1.4 \\
PV6 & -2.9 & -2.2 & 2.3 \\
PV7 & -2.1 & -3.2 & 0.1 \\
PV8 & -4.2 & -6.6 & -1.0 \\
PV9 & -6.4 & 0.2 \\
\hline
\end{tabular}

The majority of the PV modules have a real power between $2 \%$ and $8 \%$ lower than their nominal power. The presence of PV modules showing a real power higher than their nominal power corresponds to PV modules delivered with positive power tolerances, or to a BOS better than the one considered in this analysis, or a combination of both factors. Two kinds of averages can be used to characterize the distribution as a whole. The first possibility is to give the same weight to the power deviations of each PV module manufacturer (unweighted average). The second possibility, more representative of the state of the art, is to weight the power deviations of each PV module manufacturer by the total power of its modules present in the sample (weighted average). The unweighted average yields $6.3 \%$, and the weighted average yields 4.9\%. The PV module that yields the best results is also the one that sold the best in 2010. It is a module based on HIT technology. Some models of PV modules show poor quality. A relevant observation concerns a PV module based on CIS technology, showing a mean real power up to $16 \%$ below the nominal power. To investigate the reasons for such a low power, the PV systems equipped with this module have been grouped by year of installation. On average, a loss of power of $5 \%$ per year has been observed on these modules from 2007 to 2010 . The low power is thus very probably due partly to an initial low power, and partly to a light soaking degradation higher than for the other technologies. The multidimensional ANOVA allowed verifying that those conclusions about the real power of PV modules are not affected by other parameters of the installations, such as the inverters or installers.

The comments received from the users of BDPV indicate that the geographical origin of the PV modules and inverters is often taken as an indicator of quality. In particular, they tend to consider as high quality the PV components manufactured in their country or in Europe, while they often turn down PV modules manufactured in China on the sole basis of their origin. Nevertheless, the analysis of the data of BDPV has demonstrated that no clear correlation exists between the performance of PV modules and the country where they were made. For example, several Chinese manufacturers present in the database perform better than average, while several French PV modules manufacturers perform below average.

Other authors have reported the real nominal power of PV modules to be on average $5 \%$ inferior to the nominal power stated by their manufacturer $[28,31]$. Globally, those differences between real power and nominal power suggest that it is profitable to implement quality control procedures to verify and improve the quality of PV systems [32,33].

\subsection{Validation of the results against on-site measurements}

The results of the present work have been compared to on-site measurements realized by the IES-UPM during the last years on more than $200 \mathrm{MW}$ of PV modules equipping solar plants in Spain, Italy and France [28]. Among the modules manufacturers present on more than 25 installations of the database of BDPV, it was possible to identify 9 that were also measured by the IES-UPM. The relation between their real and nominal powers has been estimated by both methods, and is shown in Table 4. The difference is generally lower than $2.3 \%$. This is well within the uncertainties of those kinds of measurements. Additionally to the uncertainties on the measurements and on the estimations used in both methods, other sources of uncertainties are present from the fact that the PV modules that were rated here were not all installed at the same time, nor under the same climatic conditions, which possibly implies that some modules have already lost more power than others due to the light soaking process ongoing since they were exposed to outdoor conditions. Such agreements can thus be considered as very satisfactory. It is important to note that these conclusions are drawn only for PV modules present on at least 25 installations.

\section{Conclusions and discussion}

The objective of this paper is to review the state of the art of residential PV systems in France, which is done analyzing the operational data of 6868 PV systems. Although the available data relate to installations in Metropolitan France, the results are of general interest to understand the state of the art of residential PV in Europe.

The PV market in France developed towards residential PV systems as a consequence of limiting the most interesting public financial support to systems of a maximum of $3 \mathrm{~kW}_{\mathrm{p}}$. The PV industry (manufacturers of PV modules and inverters) is dominated by a reduced number of actors, while an important fraction of installations are realized by small installers, working at a regional scope.

On average, the PV systems produced in 2010 a net annual energy of $1163 \mathrm{kWh} / \mathrm{kW}_{\mathrm{p}}$. As a whole, the orientation of residential PV causes energy productions to be some $7 \%$ inferior to optimally oriented PV systems. These losses due to orientation are generally low enough to ensure that the PV systems installed on buildings are a viable alternative to solar plants optimally oriented.

The quality of the PV systems is quantified using the Performance Ratio (PR), and the Performance Index (PI). After a mean exposure time of 2 years, the mean value of $P R$ is $76 \%$ and the mean PI is $85 \%$, which implies that the typical real PV system produces $15 \%$ less than a reference PV system. On average, the real power of the PV modules falls $4.9 \%$ below their corresponding nominal power announced on the manufacturer's datasheet. A brief analysis by PV modules technology has led to relevant observations about two technologies. On the one hand, the PV systems equipped with HIT modules show performances higher than average. On the other hand, the systems equipped with the CIS modules show a real power that is $16 \%$ lower than nominal value.

\section{Acknowledgements}

This work would never have been possible without the thousands of altruistic people who generously and freely provided us the data corresponding to the energy production of their PV system. Catherine Praile, owing to her programmer talents, was absolutely 
essential to the success of this work. Eduardo Lorenzo brought invaluable feedback and insight.

\section{References}

[1] Statistiques EDF. Installations de production raccordées au réseau géré par ERDF à fin mars; 2011.

[2] BDPV: Base de Données PhotoVoltaïque, http://www.bdpv.fr/.

[3] Jahn U, Nasse W. Operational performance of grid-connected PV systems on buildings in Germany. Progress in Photovoltaics: Research and Applications 2004:12:441-8, doi:10.1002/pip.550.

[4] Oozeki T, Yamada T, Otani K, Takashima T, Kato K. Performance trends in grid-connected photovoltaic systems for public and industrial use in Japan. Progress in Photovoltaics: Research and Applications 2010;18:596-602. doi:10.1002/pip.992.

[5] Wiles JC, Brooks B, Schultze B. PV installations, a progress report. In: IEEE Photovoltaic Specialists Conference. 2002.

[6] Dincer F. The analysis on photovoltaic electricity generation status, potential and policies of the leading countries in solar energy. Renewable and Sustainable Energy Reviews 2011;15(January (1)):713-20, doi:10.1016/j.rser.2010.09.026. ISSN 1364-0321.

[7] Huang HS, Jao JC, Yen KL, Tsai CT. Performance and Availability Analyses of PV generation systems in Taiwan, World Academy of Science. Engineering and Technology 2011;78.

[8] Rüther R, Dacoregio M, Salamoni I, Knob P, Bussemas U. Performance of the first grid-connected, BIPV installation in Brazil over eight years of continuous operation. In: Proceedings 21st European Photovoltaic Solar Energy Conference. 2006.

[9] IEA, PVPS task 13: performance and reliability of photovoltaic systems, http://www.iea-pvps.org/index.php?id=57.

10] SoDa, http://www.soda-is.com/.

[11] PVGIS, http://re.jrc.ec.europa.eu/pvgis/

[12] Erbs DG, Klein SA, Duffie JA. Estimation of the diffuse radiation fraction for hourly, daily and monthly average global radiation. Solar Energy, Elsevier: 1982.

[13] Liu B, Jordan RC. The interrelationship and characteristic distribution of direct. diffuse, and total solar radiation. Solar Energy 1960;4:1-9.

[14] Hay JE. Calculating solar radiation for inclined surfaces: Practical approaches. Solar Energy, Elsevier; 2003.

[15] Narvarte $L$, Lorenzo E. Tracking and ground cover ratio. Progress in Photovoltaics: Research and Applications 2008;16:703-14, doi:10.1002/pip.847.

[16] Marion B. A method for modeling the current-voltage curve of a PV module for outdoor conditions. Progress in Photovoltaics: Research and Applications 2002;10(3):205-14.

[17] Skoplaki E, Palyvos JA. On the temperature dependence of photovoltaic module electrical performance: a review of efficiency/power correlations. Solar Energy, Elsevier 2009;83(5):614-24.
[18] Simon M, Meyer EL. The effects of spectral evaluation of $c$-Si modules. Progress in Photovoltaics 2011

[19] Betts T, Jardine C, Gottschalg R, Infield D, Lane $K$. Impact of spectral effects on the electrical parameters of multijunction amorphous silicon cells. In: Proceedings of 3rd World Conference on Photovoltaic Energy Conversion. 2003, vol, 2, pp. 1756-9.

[20] Schmid J, Schmidt H. Inverters for photovoltaic systems. In: Proceedings 5th Contractor's Meeting of the Photovoltaic Demonstration Projects. 1991.

[21] Hammond R, Srinivasan D, Harris A, Whitfield K. Wohlgemuth J. Effects of soiling on PV module and radiometer performance. In: AZ Photovoltaic Specialists Conference. 1997.

[22] Martin N, Ruiz JM. Annual angular reflection losses in PV modules. Progress in Photovoltaics 2006.

[23] Behnke, Erdman, Whitaker Engineering Inc. Commonwealth energy biogas/PV mini-grid, renewable resources program. In: Interim Exposure and Operations Report for the Comprehensive Large PV System Comparison; 2005.

[24] Martinez-Moreno F, Lorenzo E, Muñoz J, Moretón R. Testing of PV arrays in large grid-connected PV plants installed in Spain. In: 23rd EUPVSEC. 2008.

[25] Decker B, Jahn U. Performance of 170 grid connected PV plants in northern Germany-analysis of yields and optimization potentials. Solar Energy 1997;59:127-33.

[26] Munro DK, Blaesser G. The performance of PV systems and components in the THERMIE programme. Climate change Energy and the environment. Renewable Energy 1994;5(1-4):172-8, doi:10.1016/0960-1481(94)90368-9. ISSN 09601481.

[27] Muñoz J, Martínez-Moreno F, Lorenzo E. On-site characterisation and energy efficiency of grid-connected PV inverters. Progress in Photovoltaics: Research and Applications 2011;19:192-201, doi:10.1002/pip.997.

[28] Martinez-Moreno F, Lorenzo E, Muñoz J, Moretón R. On the testing of large PV arrays. Progress in Photovoltaics: Research and Applications 2011;19, doi:10.1002/pip.1102.

[29] Martinez-Moreno F, Munoz J, Lorenzo E. Experimental model to estimate shading losses on PV arrays. Solar Energy Materials and Solar Cells 2010;94(12):2298-303, doi:10.1016/j.solmat.2010.07.029. ISSN 0927-0248.

[30] Bletterie B. Sensitivity of photovoltaic inverters to voltage sags-test results for a set of commercial products. e \& i Elektrotechnik und Informationstechnik 2007; 122(10):349.

[31] Fraunhofer-Institut Für Solare Energysysteme ISE, Annual Report, Achievements and Results, 2007.

[32] Caamaño E, Lorenzo E, Zilles R. Quality control of wide collections of PV modules: lessons learned from the IES experience. Progress in Photovoltaics: research and applications 1999;7:137-49.

[33] Coello J, Galindo JL, Carames M, Carreño R Quality control during the supply of PV modules: fundamental key to guarantee the profitability of PV installations. In: Proceedings 23rd European Photovoltaic Solar Energy Conference. 2008. 